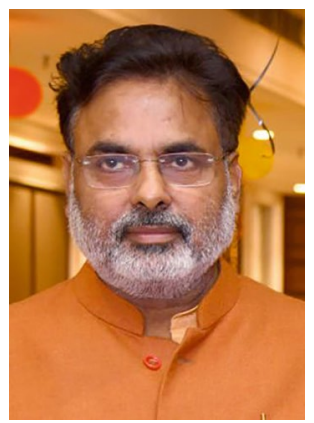

\title{
The human costs of COVID-19 policy failures in India
}

\author{
The current surge of COVID-19 cases and deaths are a result of ineffective policy \\ responses, an anti-scientific attitude, and a fragile underfunded health care system, \\ argues Vipin Bahadur Singh.
}

Credit: Vipin Bahadur

Singh

A deadly second wave of coronavirus infections is devastating the lives of people across India, leaving millions of people infected and putting stress on the country's already overtaxed health care system. Indians gasping for breath are being turned away, transferred, or set on waiting lists at overfull hospitals, because of the unavailability of beds and oxygen. The international community is astounded to see the scenes of mass death in the world's largest democracy.

This devastation would have been inconceivable a couple of months ago. Children were back in school, people were busy at their workplaces, and large crowds were enjoying themselves at festivals. At the beginning of March 2021, 7-day averages in India were around 15,000 cases per day. By late April, the rate had reached almost 350,000 . New daily cases exceeded 400,000 on 1 May and were reported to be 414,188 on 6 May 2021, the highest single-day number of new coronavirus infections recorded globally, with reported deaths exceeding 4,000 in a single day.

The massive second wave of COVID-19 sweeping through India is partly fuelled by the fast transmission of newly emerging variants, B.1.1.7 and B.1.617. Airborne transmission and infections without symptoms pose considerable challenges, and until recently, asymptomatic and presymptomatic transmission were not widely recognized in India as drivers of the spread of COVID-19. Reducing airborne transmission requires measures to avoid inhalation of infectious aerosols, such as ventilation, air filtration, reducing crowd gatherings, and wearing high-grade masks indoors. The situation requires higher-grade protection for healthcare and front-line COVID-19 warriors and the effective management of the health care systems for immediate actions to prevent the spreading of the virus.
But these measures were not strictly adopted at the early stage of the second wave in March 2021, due to political indecisiveness and lack of regard for scientific findings, despite the fact that a group of scientific advisers set up by the central government warned in the first half of March 2021 about a new and more contagious variant of the coronavirus. There is a common thread connecting the responses in India, Brazil, and last year's United States: not listening to their scientists. As the foremost leaders of the central government have been engaged in planning and managing elections in many provinces, they have ignored or delayed acting on scientific advice. Our crowd-pleasing leaders have allowed-and in some cases, even encouraged-mass gatherings. The government was probably satisfied with India's main computer simulation prediction results, which showed that the disease spread in the country was in the 'endgame' of the epidemic. Millions of largely unmasked people attended religious gatherings and election rallies. So, the carelessness of those holding political power has also partly fueled the country's coronavirus crisis.

According to World Bank data (2018), India's total health care spending is a mere $3.5 \%$ of gross domestic product (GDP), far lower than countries like the USA (16.9\%), France (11.3\%), and the UK $(10 \%)$, and also lower than in countries like Brazil (9.5\%) and South Africa (8.3\%). India's underfunded healthcare health care system is devastatingly overburdened with the surging second wave. Popular government-aided hospitals and/or medical institutes, which were already overcrowded before the epidemic, generally require guidance for better treatment. Patients report that non-medical staff attend to COVID-19 patients in most cases at the Institute of Medical Science BHU, Varanasi (in the Prime Minister's constituency); doctors and nurses are not seeing general patients of the COVID-19 ward but are consulting from a distance through a speaker.

Interestingly, the Nandurbar district of Maharashtra, with a population of 1.6 million, is exhibiting a different state of affairs, with 150 vacant beds and three oxygen plants. Owing to its adequate health care infrastructure, people from neighbouring districts and states have found respite in Nandurbar and admit themselves there. Rajendra Bharud, as Collector of Nandurbar supervising the general medical administration of the district, implemented pivotal measures after the first wave in 2020 , such as setting up liquid oxygen plants at the district hospitals; if the central government had implemented the same measures across the country, there may not have been a shortage of oxygen and beds across other districts and states.

The Indian government has missed out on a crucial opportunity to reduce the loss of life. The whole world now steps up to help the innocent victims of this deadly surge of the epidemic in India. A turning point has been reached only very recently. The government is now more focused on taking the right actions and has started to work towards meeting the most palpable and visceral crisis: the shortages of oxygen and additional hospitals and beds. During a pandemic, we depend on our government to succeed.

As we have seen from the mutated B.1.617 and B.1.1.7 variants, the SARS-CoV-2 virus will continue to mutate. For the general population, being vaccinated is not necessarily a reason to go out and live as usual again. It is not yet time to relax; a third wave is also predicted. It is challenging for leaders who are committed public servants to make further good decisions quickly without input from the scientific 
community. Both government and the public must learn to follow scientific advice to continue the fight against existing and possible new COVID-19 variants.
Vipin Bahadur Singh ${ }^{凶}$

Department of Physics, Udai Pratap College, Varanasi, India.

$\square \bigotimes_{e-m a i l}$ vipin2_vns@rediffmail.com
Published online: 26 May 2021

https://doi.org/10.1038/s41562-021-01140-6

Competing interests

The author declares no competing interests. 